REVISTA X, Curitiba, volume 13, n.1, p. 323-350, 2018.

Dossiê Especial: Português como Língua Adicional em contextos de minorias:

(co)construindo sentidos a partir das margens

BIZON \& DINIZ (Orgs.)

\title{
ENSINO DE PORTUGUÊS COMO LÍNGUA ADICIONAL NA UNIVERSIDADE FEDERAL DO AMAPÁ: AÇÕES DE POLÍTICA DE LÍNGUAS EM CONTEXTO DE INTERNACIONALIZAÇÃO
}

\author{
Teaching Portuguese as an Additional Language at the Federal University of \\ Amapá: Language Policy Actions in the Context of Internationalization
}

Tiêgo Ramon dos Santos ALENCAR, IEL/UNICAMP ${ }^{1}$

\begin{abstract}
RESUMO: Este trabalho objetiva traçar um breve panorama de ações de políticas de ensino de Português Língua Adicional (PLA) na Universidade Federal do Amapá (UNIFAP) e analisar de que forma essas ações foram concebidas como parte da construção de políticas de internacionalização (BIZON, 2013; ANDREOTTI et. al, 2015; SHOHAMY, 2006; SPOLSKY, 2004;) na instituição. Para tanto, à luz de uma pesquisa qualitativo-interpretativista (LANKSHEAR; KNOBEL, 2008; MAHER, 2010; TEIXEIRA, 2010), foram realizadas entrevistas semi-estruturadas e conversas informais com professores da UNIFAP, bem como consultas a informações em sites com o domínio da universidade. De maneira geral, constatou-se que as ações elencadas são em nível de extensão e que foram originadas a partir da aplicação do Certificado de Proficiência em Língua Portuguesa para Estrangeiros. Constatou-se ainda que as ações são recentes e que, para serem executadas, foi exigido um esforço maior de agentes sociais locais, os quais, na maioria das vezes, não encontraram o devido apoio. Nesse cenário, advoga-se pela potencialização da área de PLA na UNIFAP por meio de ações que sejam fruto de diálogos efetivos entre horizontalidades e verticalidades (M. SANTOS, 2001).
\end{abstract}

Palavras-chave: Português Língua Adicional; Amapá; Universidade; Internacionalização; Políticas Linguísticas.

ABSTRACT: This paper aims to illustrate a brief overview of the actions of policies of teaching Portuguese as Additional Language (PLA) at the Federal University of Amapá (UNIFAP) and to analyze how these actions were conceived as part of the internationalization (BIZON, 2013; ANDREOTTI et. al, 2015) policies in the institution. In order to do so, based on a qualitative-interpretative research (LANKSHEAR; KNOBEL, 2008; MAHER, 2010; TEIXEIRA, 2010), semi-structured interviews and informal conversations with UNIFAP professors were carried out, as well as information on websites with university domain were viewed. In general, it was concluded that the actions listed are at the extension level and that they were originated

\footnotetext{
${ }^{1}$ Mestrando em Linguística Aplicada - Bolsista CAPES Email: tiegoramon@ gmail.com
} 
REVISTA X, Curitiba, volume 13, n.1, p. 323-350, 2018.

Dossiê Especial: Português como Língua Adicional em contextos de minorias:

(co)construindo sentidos a partir das margens

BIZON \& DINIZ (Orgs.)

from the application of the Certificate of Proficiency in Portuguese Language for Foreigners. On the other hand, it was revealed that the actions are recent and that, for their executions, needed a greater effort from local social agents, who, for the most part, did not find the due support. In this scenario, we claim for the potencialization of the PLA area in UNIFAP, whose actions are the result of effective dialogues between horizontalities and verticalities (M. SANTOS, 2001).

Keywords: Portuguese as Additional Language; Amapá; College; Internationalization; Language Policies.

\section{INTRODUÇÃO}

A expansão do ensino de Português Língua Adicional (PLA) ${ }^{2}$ nas Instituições de Ensino Superior (IES) no Brasil vem se intensificando, justificada, em grande medida, pelas crescentes demandas de internacionalização das universidades internacionalização esta que não pode ser desvinculada dos processos de globalização (BIZON, 2013; STEIN; ANDREOTTI, 2015).

Embora possa parecer que ações de internacionalização do ensino superior tenham se iniciado no século XXI, elas não são recentes, como bem destaca Krawczyk (2008). As primeiras universidades, surgidas ainda na Idade Média na Europa, configuraram-se a partir de uma matriz de internacionalidade, já que se constituíam como locais de encontro de estudantes e pensadores provenientes de diferentes lugares do mundo. No Brasil, mesmo com a recente história das IES vale destacar que, há mais de 50 anos, o país vem trazendo às nossas universidades estudantes estrangeiros por meio do Programa Estudantes Convênio de Graduação (PEC-G) $)^{3}$. Surgido na década de

\footnotetext{
${ }^{2}$ Neste trabalho, assumo o termo "língua adicional" por acreditar que a noção de repertório linguístico e de acréscimo a outras línguas já tidas pelo aluno é mais significativa do que a distinção entre "nativo" e "estrangeiro" por vezes implicada no termo "língua estrangeira" (BIZON, 2013, p. 3). Nessa perspectiva, Diniz (no prelo), amparado em Rajagopalan (1997), salienta que "o termo língua adicional representa um posicionamento político de crítica ao mito do falante nativo, amplamente problematizado no campo da Linguística Aplicada". Conforme pontua o autor, a opção por este termo marca "a heterogeneidade do espaço de enunciação do português - seja no Brasil, seja em outros países da CPLP -, fazendo face ao silenciamento, historicamente produzido, das diferentes línguas constitutivas desse espaço". Assim, neste artigo, o uso do termo "língua estrangeira" será mantido apenas em citações e nas narrativas dos participantes de pesquisa.

${ }^{3}$ Maiores informações sobre o programa podem ser consultadas na página do convênio no site do Ministério das Relações Exteriores, disponível em:< http://www.dce.mre.gov.br/PEC/PECG.php>Acesso em: 10 jul. 2018.
} 
REVISTA X, Curitiba, volume 13, n.1, p. 323-350, 2018.

Dossiê Especial: Português como Língua Adicional em contextos de minorias:

(co)construindo sentidos a partir das margens

BIZON \& DINIZ (Orgs.)

1920 e formalizado em 1965, tal programa já trouxe ao país mais de 25 mil estudantes (BIZON, 2013), tendo papel importante na mobilidade estudantil e na configuração da internacionalização das instituições de ensino superior brasileiras desde a sua criação, embora pouco se fale sobre ele.

Da mesma forma, a globalização, fundamental para compreender a atual demanda de internacionalização das IES, não é um fenômeno recente, tendo nascido a partir da exploração e conquistas europeias, bem como da formação dos mercados capitalistas mundiais (HALL, 2009 [2003]). Nos dois últimos séculos, porém, esse processo teve seu ritmo acelerado pelo avanço da ciência e da tecnologia - o que implica, diretamente, a educação superior, já que são estes dois dos grandes eixos norteadores das ações das IES. Por isso, na perspectiva de Pennycook (2006; 2007, apud BIZON, 2013), é importante considerar o processo histórico da globalização para que se compreenda a influência deste não apenas no mundo dos negócios, como também na Educação, na Saúde e no Transporte - na vida cotidiana, afinal.

Apoio-me nas considerações feitas por Bizon (ibidem) para afirmar que a internacionalização, tão buscada pelas IES nos dias atuais, é um reflexo do processo de globalização que, por vezes, pode assumir traços de perversidade (M. SANTOS, 2001), justamente por deixar à margem aqueles atores sociais considerados inaptos a mobilizar determinados conhecimentos exigidos pela complexificação das técnicas e tecnologias que marcam a sociedade atual.

A globalização, assim configurada, faz emergir o que Andreotti et al. (2015, p. 22) denomina de "violências da modernidade", dentre as quais se destacam as desigualdades no ensino superior presentes no âmbito da internacionalização. Um exemplo dessa violência e consequente desigualdade pode ser constatada em processos de racialização sofridos e relatados por estudantes estrangeiros ${ }^{4}$ em contexto de mobilidade acadêmica (STEIN; ANDREOTTI, 2015). Atribuindo o notável aumento do número de intercambistas ao "imaginário global dominante" de que o Norte Ocidental é superior, Stein e Andreotti (ibidem) chama a atenção para o fato de que o ensino

\footnotetext{
${ }^{4}$ Acerca dos problemas enfrentados por estudantes estrangeiros no Brasil, ver Bizon (2013) e Miranda (2016).
} 
REVISTA X, Curitiba, volume 13, n.1, p. 323-350, 2018.

Dossiê Especial: Português como Língua Adicional em contextos de minorias:

(co)construindo sentidos a partir das margens

BIZON \& DINIZ (Orgs.)

superior Ocidental é visto como um "produto" desejado por estudantes estrangeiros que, a um só tempo, se orientam por esse imaginário e sofrem as consequências das ações daqueles que, também guiados por esse imaginário, frequentemente os subalternizam. Tendo isso em vista, reitero a importância de se considerar a globalização não como uma "fábula" (M. SANTOS, 2001, p. 18), mas como um processo que contribui para o surgimento das ditas violências da modernidade.

Nesse sentido, é relevante salientar que os atores sociais envolvidos nos processos de globalização fazem parte de uma horizontalidade, a qual corresponde ao que Milton Santos (ibidem) chama de espaço das vivências. É nas agências cotidianas das horizontalidades que se configura o social e sua "variedade de racionalidades e tempos, permitindo que as produções sejam voltadas aos interesses locais e realizadas dentro de uma área que também constitui um fator de produção" (BIZON; CAMARGO, 2018, p. 716). Em contrapartida, as verticalidades são detentoras de uma “ordem implacável" (SANTOS, 2001) e correspondem aos espaços de fluxos que implicam diretamente o surgimento de agentes de poderes hegemônicos, dentre os quais se pode destacar o Estado e suas diversas instituições.

Assim, alinhando-me à perspectiva de internacionalização defendida por Bizon (ibidem), afirmo ser necessário minimizar o tanto quanto possível as desigualdades causadas pelas discrepâncias entre os interesses das horizontalidades e verticalidades. Para isso, são fundamentais projetos que "não visem apenas a números ou se concretizem em via de mão única" (BIZON, idem, p. 48), nem se configurem como violentos/opressores (ANDREOTTI et al., ibidem, p. 31), mas, ao contrário, promovam diálogos multilaterais com os mais diferentes parceiros, buscando operacionalizar ações que contribuam para a inserção desses parceiros no meio acadêmico e em seu entorno. Considerando especificamente o contexto de pesquisa que este artigo focaliza, destaco também a necessidade de construir e viabilizar políticas de internacionalização em locais que, por estarem geograficamente distantes dos centros de maior poder econômico e político e por serem frequentemente narrados como margens, têm, a princípio, menos possibilidades de desenvolvimento dessas ações, como é o caso do estado do Amapá. 
REVISTA X, Curitiba, volume 13, n.1, p. 323-350, 2018.

Dossiê Especial: Português como Língua Adicional em contextos de minorias:

(co)construindo sentidos a partir das margens

BIZON \& DINIZ (Orgs.)

Nessa perspectiva, este trabalho tem por objetivo traçar um panorama de ações de política de ensino de Português como Língua Adicional na Universidade Federal do Amapá (UNIFAP), como parte de uma política de internacionalização (BIZON, ibidem; ANDREOTTI et. al, ibidem; M. SANTOS, ibidem; STEIN; ANDREOTTI, ibidem), discutindo de que forma essas ações foram geradas em um contexto de recente inserção do PLA na instituição. Além desta introdução, o artigo apresenta quatro seções. Na primeira, teço uma breve contextualização sobre o estado do Amapá e sobre a UNIFAP (F. SANTOS, 2000; AMAPÁ, 2009) e, em seguida, apresento a concepção de política linguística (SPOLSKY, 2004; SHOHAMY, 2006) assumida na investigação. Na segunda seção, detalho a metodologia de pesquisa (LANKSHEAR; KNOBEL, 2008; MAHER, 2010; TEIXEIRA, 2010), enquanto, na terceira, seção central deste trabalho, elenco e analiso as seis ações de políticas de ensino de PLA na UNIFAP executadas no período de 2014 a 2017. Por fim, na quarta seção, considerando essas ações em um contexto recente de internacionalização, aponto algumas implicações para uma significativa potencialização do ensino de PLA na UNIFAP, de modo a evidenciar um diálogo mais significativo entre horizontalidades e verticalidades.

\section{A(S) MARGEM(NS): O AMAPÁ E A UNIVERSIDADE FEDERAL DO AMAPÁ}

As origens do estado do Amapá enquanto território brasileiro datam do século XVIII, quando Macapá, que até então não era capital, foi promovida à condição de vila (F. SANTOS, 2000) e o território físico do estado foi doado ao português Bento Manuel Parente, que o nomeou "Capitania da Costa do Cabo Norte". Devido às grandes fontes de recursos naturais e às questões fronteiriças características da região, houve grande interesse pela exploração por parte de holandeses, franceses e ingleses. Este conflito exploratório no Amapá perdurou até o início do século passado, quando a Comissão de Genebra, responsável pela atribuição ou não de terras a determinadas nações e pela mediação de conflitos (como os embates entre França e Brasil, por exemplo), deu a posse do território ao Brasil, que o incorporou ao estado do Pará com o nome de 
REVISTA X, Curitiba, volume 13, n.1,p. 323-350, 2018.

Dossiê Especial: Português como Língua Adicional em contextos de minorias:

(co)construindo sentidos a partir das margens

BIZON \& DINIZ (Orgs.)

Araguari $^{5}$ (AMAPÁ, 2009). Isso se deu graças à defesa do diplomata José Maria Paranhos da Silva Filho, o Barão do Rio Branco $^{6}$ que defendeu a atribuição das terras ao lado brasileiro - o que foi concedido na data de $1^{\circ}$ de maio de 1900.

Anos mais tarde, em 13 de setembro de 1943, o Decreto Federal n ${ }^{\circ} 5.812$ criou o Território Federal do Amapá, desmembrando a área do então estado do Pará. É significativo observar que, durante 45 anos, o Amapá se manteve "sob a jurisdição direta do Executivo Federal" (AMAPÁ, 2009, p. 4) e, apenas em 1988, com a promulgação da Constituição da República Federativa do Brasil, o território foi elevado à condição de estado. No entanto, a autonomia com relação à estruturação governamental (eleições diretas e institucionalização de casas de lei - prefeitura e assembleia legislativa, por exemplo) aconteceu somente em 1990, quando foram eleitos os primeiros membros da administração (governadores, deputados e senadores).

Este contexto de emancipação do Amapá foi primordial para a criação da Universidade Federal do Amapá, em 1990. Cabe ressaltar que, antes de ser fundada, a UNIFAP já havia iniciado suas atividades mas não com o título de universidade: em 1970, o Núcleo Avançado de Ensino (NEM) foi instituído na região como forma de promover o ensino superior, na modalidade de magistério (licenciatura curta). O NEM era vinculado à Universidade Federal do Pará (UFPA) e foi a alternativa encontrada pelos governantes da época para levar capacitação a uma área que ainda não contava com instituições formais de ensino superior ${ }^{7}$.

Hoje, 26 anos após sua fundação, a UNIFAP possui 4 campi, nas cidades de Macapá, Santana, Oiapoque e Mazagão, além de polos de educação a distância. Em 2015, em comemoração aos 25 anos de existência, foi lançado o Plano de Desenvolvimento Institucional (PDI $)^{8}$ da UNIFAP, que tem por objetivos centrais fomentar, visibilizar e propor ações de desenvolvimento da universidade não apenas em

\footnotetext{
${ }^{5}$ Nome de um dos rios que banham o estado.

${ }^{6}$ Hoje, em reconhecimento ao excepcional trabalho exercido pelo Barão, o instituto responsável pela formação de diplomatas, em Brasília, chama-se Instituto Rio Branco. Além disso, no Amapá, a escola mais antiga do estado leva o nome do diplomata.

${ }^{7}$ Informações retiradas do site da reitoria da UNIFAP. Disponível em: <http://www2 .unifap. br/ reito ria/ 2015 / 10/09/historico-da-unifap/>. Acesso em: 4 abr. 2017.

${ }^{8}$ Plano de Desenvolvimento Institucional da UNIFAP. Disponível em: <_http://www2. unifap.br/ pdi/ files/ 2009 / 08/PDI-2015-2019-UNIFAP.pdf>. Acesso em: 2 jun. 2017.
} 
REVISTA X, Curitiba, volume 13, n.1, p. 323-350, 2018.

Dossiê Especial: Português como Língua Adicional em contextos de minorias:

(co)construindo sentidos a partir das margens

BIZON \& DINIZ (Orgs.)

âmbito amapaense, como nacional e internacional. Este plano está em execução e prevê que, até 2019, os objetivos propostos sejam atingidos.

\section{POLÍTICA(S) LINGUÍSTICA(S): UMA VISÃO AMPLIADA}

As ações da universidade aqui elencadas serão consideradas como ações que se configuram como políticas linguísticas. Embora alguns autores considerem a distinção entre política linguística e planejamento linguístico (CALVET, 2007), alinho-me aos preceitos de Spolsky (2004) e Shohamy (2006), cujas teorizações propõem a ampliação do entendimento de política linguística, tendo em vista o sentido central de que a maioria das políticas concebidas estão mais no campo das representações e práticas linguísticas do que, de fato, das políticas "verticais” efetivadas por órgãos oficiais.

Quanto ao funcionamento dessas políticas linguísticas, Spolsky (ibidem) reafirma a importância de concebê-las ainda que não tenham sido implementadas oficialmente. $\mathrm{O}$ autor chama a atenção para o fato de que é preciso ter um olhar crítico em relação a essas políticas, especialmente no caso de não terem sido documentadas de forma oficial em texto legislativo - uma vez que isso recai, necessariamente, sobre práticas e representações da comunidade situada no facto (SHOHAMY, ibidem). Em suma, deve-se entender políticas linguísticas como decisões relacionadas ao(s) uso(s) que se faz da língua, tendo essas decisões (ou não) respaldo oficial.

Com isso, Shohamy (2006) indica duas grandes distinções entre essas políticas: políticas linguísticas oficiais e políticas linguísticas de facto. As políticas linguísticas oficiais, conforme explicitado anteriormente, apresentam legitimidade no que diz respeito ao respaldo documental. Para Shohamy (ibidem) o que se configura no escopo do oficial é instituído da/na esfera macro para a esfera micro, considerando ações deliberadas em instâncias como o Estado ou outros organismos de igual ou maior importância. É relevante ressaltar um possível alinhamento entre a esfera do oficial com o que Milton Santos (2001) denomina de verticalidade - o eixo que ordena e é caracterizado pela hegemonia. 
REVISTA X, Curitiba, volume 13, n.1, p. 323-350, 2018.

Dossiê Especial: Português como Língua Adicional em contextos de minorias:

(co)construindo sentidos a partir das margens

BIZON \& DINIZ (Orgs.)

Por outro lado, as políticas linguísticas de facto se configuram em ações pensadas em âmbito local e operacionalizadas a partir de necessidades específicas de um dado contexto. O caráter menos formal das políticas linguísticas de facto evidencia, por vezes, movimentos de resistência com relação às ações oficiais - as quais podem ser remetidas à concepção de horizontalidades de Santos (idem), ou seja, como o eixo do social e das vivências cotidianas daqueles que, direta ou indiretamente, respondem a uma verticalidade. Neste artigo, a título de exemplificação, será possível visualizar de que forma estes contrapontos entre as políticas oficiais e as políticas de facto são construídos nas políticas da IES analisada.

Ademais, sobre a relação entre as políticas linguísticas oficiais e as de facto, de acordo com Silva (2016),

\begin{abstract}
no modelo desenvolvido por Shohamy, mesmo as políticas linguísticas oficiais podem não refletir as políticas de facto, pois, muitas vezes, são apenas cartas de intenções do Estado. [...] As políticas linguísticas de facto são determinadas por vários mecanismos ou dispositivos políticos (policy devices), ou seja, por canais em que as políticas linguísticas são reproduzidas e manifestadas na sociedade (SILVA, 2016, pp. 77-78).
\end{abstract}

Logo, deve-se ressaltar que, por vezes, gestos realizados no âmbito de uma política linguística oficial não se concretizam por meio de uma política linguística de facto. A autora menciona ainda, amparada em Shohamy (ibidem), que são vários os mecanismos pelos quais as políticas linguísticas são operacionalizadas na sociedade, inclusive de forma conjunta. Assim, é possível que existam políticas linguísticas de facto que também sejam oficiais, como por exemplo, o próprio Celpe-Bras, exame oficial de proficiência em português, desenvolvido pelo Ministério da Educação brasileiro e que tem exercido efeitos importantes na área de PLA, tanto no Brasil quanto no exterior.

Tendo isso posto, para o levantamento das políticas construídas pela UNIFAP, trago a seguir o detalhamento dos procedimentos realizados nesta pesquisa. 
REVISTA X, Curitiba, volume 13, n.1, p. 323-350, 2018.

Dossiê Especial: Português como Língua Adicional em contextos de minorias:

(co)construindo sentidos a partir das margens

BIZON \& DINIZ (Orgs.)

\title{
METODOLOGIA E PROCEDIMENTOS DE PESQUISA
}

A pesquisa cujos dados são discutidos neste trabalho é de base qualitativointerpretativista, a qual, segundo Teixeira (2010), procura diminuir a distância entre a teoria e os dados, partindo da compreensão do fenômeno estudado por meio de sua descrição e interpretação. Em concordância com Lankshear e Knobel (2008, p. 66), a pesquisa qualitativa tenta entender "[...] como as pessoas experimentam, entendem, interpretam e participam de seus mundos social e cultural [...]". Nesse sentido, Maher (2010, p. 39), ao tratar do papel do pesquisador, ressalta que

\begin{abstract}
o pesquisador não registra, simplesmente, o que as pessoas dizem. Nós somos agentes cruciais na micropolítica de elicitação de dados porque nossa própria presença determina, mesmo que em parte, o que os sujeitos pesquisados nos dizem. Além disto, nossa seleção do que é relevante para análise, assim como essa em si, estão contaminadas pela nossa história pessoal, por nosso posicionamento ideológico.
\end{abstract}

Nas palavras da pesquisadora, nessa perspectiva, a geração de registros não é um instrumento de "coleta de dados", uma vez que estes não estão prontos para serem coletados, a priori. Este olhar para o corpus da pesquisa, além da análise de contextos sociais específicos, propõe possíveis intervenções nesses contextos, de forma que os "tipos dominantes de realidades sociais e de identidades" (THREADGOLD, 2005) sejam modificados, transformando, também, as narrativas dos participantes.

Tendo tais preceitos metodológicos como direcionadores, a geração de registros ocorreu na Universidade Federal do Amapá, por meio de entrevistas semi-estruturadas (FLICK, 2009) e de conversas informais feitas com professores envolvidos com o PLA na instituição. As gravações das entrevistas semi-estruturadas foram realizadas em um aparelho celular, tipo smartphone, e duraram, em média, meia hora cada. As conversas informais, no caso de impossibilidade de realização presencial, foram feitas por meio de redes sociais on-line, como WhatsApp e Facebook. Para preservar a identidade ${ }^{9}$ dos

\footnotetext{
${ }^{9}$ Como parte do processo de anonimização, optei por não indicar o gênero dos participantes de pesquisa.
} 
REVISTA X, Curitiba, volume 13, n.1, p. 323-350, 2018.

Dossiê Especial: Português como Língua Adicional em contextos de minorias:

(co)construindo sentidos a partir das margens

BIZON \& DINIZ (Orgs.)

participantes da pesquisa, designei siglas para cada um deles: P1, P2, P3 e P4 ${ }^{10}$. Dentre eles, havia docentes dos cursos de Letras/Francês e do curso de Relações Internacionais da UNIFAP, além de um estudante do curso de Letras/Inglês da UNIFAP.

Por fim, foram consultadas, em sites da UNIFAP ${ }^{11}$, informações sobre as ações relacionadas ao PLA na instituição. Tais informações contemplam desde notícias acerca de cursos de extensão até editais de seleção.

\section{AS AÇÕES: POLÍTICAS DE INTERNACIONALIZAÇÃO E ENSINO- APRENDIZAGEM DE PORTUGUÊS LÍNGUA ADICIONAL}

Nesta seção, elenco e analiso as seis ações de políticas de línguas realizadas pela UNIFAP no que diz respeito ao ensino de PLA. São elas: (1) a aplicação do Certificado de Proficiência em Língua Portuguesa para Estrangeiros - Celpe-Bras; (2) o curso livre de Português para Estrangeiros com foco no Celpe-Bras (2014); (3) o curso "Português para Estrangeiros" (2015); (4) o curso de Pronúncia em Português para Falantes de Espanhol (2016); (5) o curso de Português para Iniciantes (2016) e (6) o curso de Português para Candidatos ao Programa de Estudantes-Convênio de Graduação - PECG (2017).

Como ponto de partida para a análise, trago um parágrafo do Plano de Desenvolvimento Institucional da UNIFAP mencionado anteriormente, que aponta a internacionalização como um dos eixos centrais para o desenvolvimento da instituição:

OBJETIVO: Intensificar a internacionalização.

DESCRIÇÃO DO OBJETIVO: Articular-se com instituições internacionais, promovendo ações e parcerias que visem à cooperação científica, tecnológica e cultural por meio de projetos conjuntos de ensino, pesquisa e extensão e

\footnotetext{
${ }^{10}$ Há, também, um docente que se faz presente nos discursos dos professores entrevistados e que esteve envolvido na oferta dos cursos de PLA na UNIFAP. Porém, desde 2016, ele não se encontra mais na instituição e, apesar de ter tentado alguns contatos por e-mail, não obtive êxito ao tentar realizar a entrevista semi-estruturada ou mesmo uma conversa informal. Em virtude disso, não o inseri como participante de pesquisa, mas, considerando a sua relevância nos discursos dos professores entrevistados, optei por denominá-lo P5, não o omitindo desses discursos e preservando, igualmente, sua identidade.

${ }^{11}$ Todos os sites tem o domínio .unifap.br.
} 
REVISTA X, Curitiba, volume 13, n.1, p. 323-350, 2018.

Dossiê Especial: Português como Língua Adicional em contextos de minorias:

(co)construindo sentidos a partir das margens

BIZON \& DINIZ (Orgs.)

intercâmbio de docentes, pesquisadores, alunos e técnicosadministrativos.

A partir desse trecho, é possível inferir a importância da internacionalização para o crescimento da universidade, no tripé que sustenta a universidade - ensino, pesquisa e extensão. Destaco que, como este artigo foi concebido em um momento de expressivo desenvolvimento da instituição, outras ações podem ter surgido. Contudo, para efeitos de recorte temporal para geração de registros, será abrangido o decênio 2007-2017.

\section{O Certificado de Proficiência em Língua Portuguesa para Estrangeiros - Celpe- Bras -(2007)}

A primeira grande ação relacionada ao ensino-aprendizagem de PLA na UNIFAP foi o credenciamento da universidade para aplicação do Certificado de Proficiência em Língua Portuguesa para Estrangeiros - Celpe-Bras, em 2007. Esta informação foi concedida por P1:

Pesquisador: Então, P1, como aconteceu esse início do Português como Língua Estrangeira ${ }^{12}$ na UNIFAP?

P1: Antes... não tinha essa preocupação do PLE [Português Língua Estrangeira $]^{13}$. Eu coordeno a aplicação do Celpe-Bras desde que começou, em... 2007. E só de uns anos pra cá que foram surgir essas ações [voltadas para o PLA]. Antes eram mais ou menos 10, 15 inscritos por edição, mas hoje a procura aqui é maior.

Pesquisador: Nesse caso, você considera o Celpe-Bras como o início do PLE na UNIFAP?

P1: Sim, sim. Depois do Celpe-Bras que a gente começou a pensar em ações de Português para estrangeiro. (Entrevista concedida em 12/07/2017)

Como evidencia o relato, o credenciamento foi realizado em 2007. O professor em questão situa o exame como o marco central para que políticas de implementação do PLA se iniciassem na instituição, o que reafirma o potencial de exames avaliativos

\footnotetext{
${ }^{13}$ As inserções entre colchetes - [ ] - são comentários meus, em caráter de esclarecimento.
} 
REVISTA X, Curitiba, volume 13, n.1, p. 323-350, 2018.

Dossiê Especial: Português como Língua Adicional em contextos de minorias:

(co)construindo sentidos a partir das margens

BIZON \& DINIZ (Orgs.)

provocarem efeitos retroativos (SCARAMUCCI, 2012) tanto no ensino quanto em políticas mais amplas a ele relacionadas.

Por outro lado, é relevante mencionar que, até a elaboração e oferta do primeiro curso - ação que será descrita a seguir -, P1 sentia-se incomodado com a discrepância entre a realização do exame e a ausência de políticas de ensino de PLA na instituição. Sobre isso, declara:

P1: Sobre o PLE, é complicado ver que a universidade não encara a área como deveria, ainda mais em contexto de fronteira como é o caso do Amapá. Eu já aplico o Celpe faz muito tempo... quase dez anos. [...] E só em 2014 foi surgir um curso de extensão, isso partindo de nós, professores.

[...] Estamos reformulando o Projeto Político-Pedagógico dos cursos de Letras e estamos pensando na oferta de disciplinas optativas que contemplem o PLE até mesmo pensando não só no ensino mas no Celpe também, onde tudo começou. (Entrevista concedida em 12/07/2017)

Conforme consta no depoimento, P1 afirma que, embora estivesse envolvido com a aplicação do Celpe-Bras há quase dez anos, passaram-se anos até que fosse implementada uma primeira ação de política de línguas na universidade. Atribuindo a falta de reconhecimento da área de PLA na UNIFAP ao fato de a universidade não encarar a área como deveria e por esquecer o contexto fronteiriço no qual ela se insere, P1 indica ações futuras como a reformulação do Projeto Político-Pedagógico dos cursos de Letras da instituição, provavelmente como forma de melhor visibilizar a área de PLA.

A meu ver, tal ação se configura como um efeito retroativo da implementação do Celpe-Bras na UNIFAP, “onde tudo começou”, segundo P1, e que, consequentemente, acarreta outras ações subsequentes que passam a incluir a formação não apenas de professores, mas também de profissionais que possam atuar no âmbito do exame. Em relação a possíveis efeitos da implementação do Celpe-bras, Scaramucci (2012, p. 49) afirma: 
REVISTA X, Curitiba, volume 13, n.1, p. 323-350, 2018.

Dossiê Especial: Português como Língua Adicional em contextos de minorias:

(co)construindo sentidos a partir das margens

BIZON \& DINIZ (Orgs.)

Embora tenhamos clareza de [...] que a implementação de um exame per se não seja suficiente para que mudanças no ensino $\mathrm{e}$ aprendizagem ocorram, demandando ações paralelas de formação do professor, consideramos que, pela sua natureza, o exame Celpe-Bras seja, potencialmente, capaz de direcionar não apenas as práticas de ensino e de aprendizagem, mas também as ações de formação do professor, mesmo não sendo um exame voltado para a avaliação desse público alvo.

É nesse sentido que se pode afirmar que o credenciamento da IES para a aplicação do exame Celpe-Bras tenha, possivelmente, orientado as demais ações elencadas neste artigo. Segundo evidencia a primeira fala de P1, foi a partir do exame que se "começou a pensar em ações de Português para estrangeiro". Embora pareça evidente que o Celpe-Bras tenha despertado no professor e nos demais envolvidos em sua aplicação o interesse em ações de ensino de PLA, é importante salientar que um longo espaço de tempo após o credenciamento foi necessário para que a primeira ação, a qual veremos no próximo tópico, pudesse ser estruturada de fato.

\section{Curso livre de Português para Estrangeiros com foco no Celpe-Bras}

A matéria ilustrada na Figura 1, abaixo, e veiculada na homepage da UNIFAP em 02/10/2014, noticia a primeira ação diretamente ligada ao ensino aprendizagem de PLA na instituição, o Curso livre de Português para Estrangeiros com foco no

\section{Celpe-Bras.}

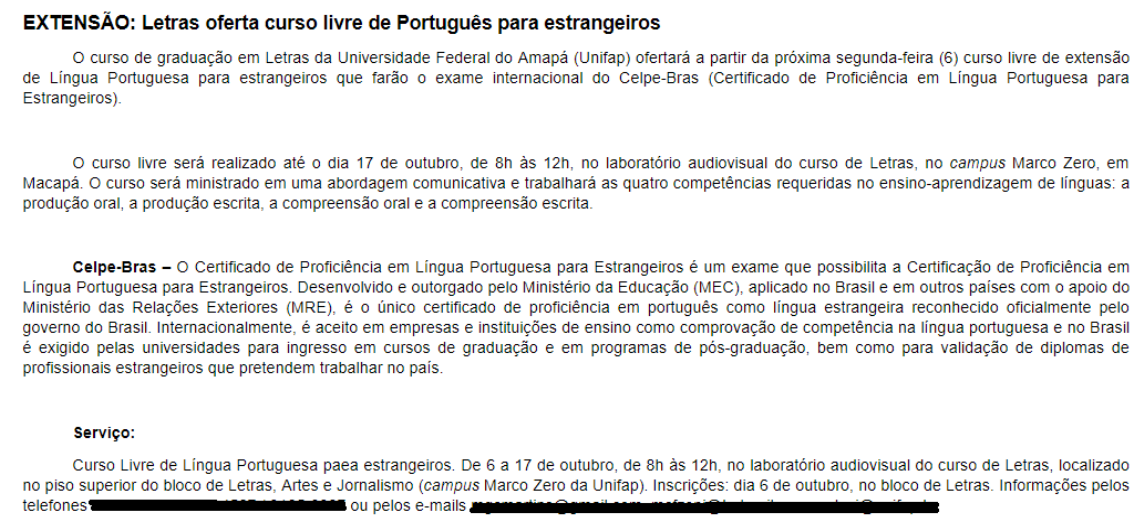

Figura 1: Notícia extraída da homepage da UNIFAP

Fonte: http://www.unifap.br/public/index/view/id/5909 
REVISTA X, Curitiba, volume 13, n.1, p. 323-350, 2018.

Dossiê Especial: Português como Língua Adicional em contextos de minorias:

(co)construindo sentidos a partir das margens

BIZON \& DINIZ (Orgs.)

O curso em foco, no âmbito da extensão, surgiu apenas em 2014, sete anos após o início da aplicação do Celpe-Bras na instituição e, como é possível constatar, foi inteiramente voltado ao exame, o que reforça o potencial de instrumentos de avaliação como direcionadores de políticas de ensino e de aprendizagem da língua (SCARAMUCCI, 2012).

Segundo relata P1, este curso foi pensado de maneira "informal":

Pesquisador: Como este curso foi concebido?

P1: Nesse primeiro a gente focou no Celpe-Bras. A gente focava mesmo na escrita, sentava com eles, trabalhava diretamente com a prova, simulava situações da prova. Primeiramente a gente pensou pro Celpe-Bras mesmo, sem ser de Português pra estrangeiro. Aí a gente começou com esse curso, de 40 horas, a gente fez... simulou avalições orais, entrevista... $\mathrm{E}$ teve os nossos monitores, que ajudavam também... E funcionou bem! Todos... quase todos se saíram bem na prova.

Pesquisador: Mas este curso teve alguma formalidade? Tipo sair um edital, uma convocatória, algo assim?

P1: Não, se eu não me engano saiu uma notícia no site da universidade, mas foi só. Inclusive essa iniciativa partiu do P5, aí eu ajudei porque era... e sou envolvido com o Celpe-Bras. (Entrevista concedida em 13/07/2017)

A narrativa de P1 sugere que a elaboração e a oferta do primeiro curso de PLA na UNIFAP aconteceu de forma não institucionalizada, já que tudo foi gerenciado pelo próprio professor e por um de seus colegas, o qual denominei P5. Isso, segundo Shohamy (2006), é o que caracteriza uma política linguística de facto, uma vez que partiu de uma necessidade local - neste caso, da percepção dos professores, de que existia uma demanda por parte dos candidatos ao Celpe-Bras que moravam na região e não possuíam a certificação em língua portuguesa - e que não houve, aparentemente, influência direta de uma política oficial.

Tendo isso em vista, pontuo também a indicação que P1 faz da ausência de apoio de outras instâncias da universidade, havendo "só" o apoio com a divulgação da notícia no site. A estruturação do curso, a elaboração de materiais didáticos e até mesmo a ajuda de monitores voluntários para o curso surgiram exclusivamente por iniciativa dos próprios docentes - o que indica, assim, um movimento forte de construção de políticas linguísticas de facto. 
REVISTA X, Curitiba, volume 13, n.1, p. 323-350, 2018.

Dossiê Especial: Português como Língua Adicional em contextos de minorias:

(co)construindo sentidos a partir das margens

BIZON \& DINIZ (Orgs.)

\section{Curso "Português para Estrangeiros"}

O curso Português para Estrangeiros, a segunda ação relacionada ao ensino de PLA, foi, assim como a ação anteriormente descrita, um curso de extensão, ofertado em 2015. Distanciando-se da informalidade característica do primeiro curso, este contou com a publicação de um edital de seleção de alunos estrangeiros, como mostra o trecho em destaque:

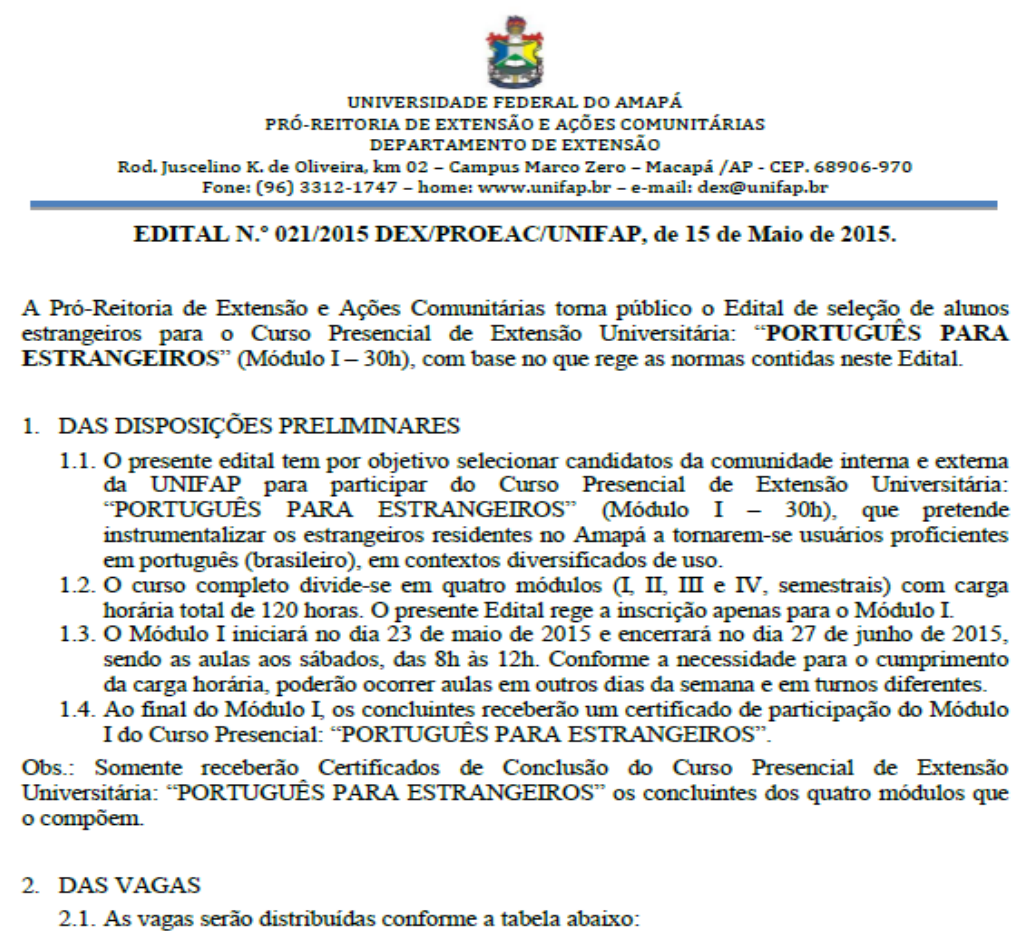

Figura 2: Fragmento de edital de seleção para curso de Português para Estrangeiros

Fonte: http://www.unifap.br/public/index/view/id/6544

O edital discrimina detalhadamente os passos para a realização do curso, tais como carga horária (120 horas divididas em 4 módulos de 30 horas cada), duração (23 de maio de 2015 a 27 de junho de 2015, nas manhãs de sábado) e público-alvo (alunos 
REVISTA X, Curitiba, volum e 13, n.1, p. 323-350, 2018.

Dossiê Especial: Português como Língua Adicional em contextos de minorias:

(co)construindo sentidos a partir das margens

BIZON \& DINIZ (Orgs.)

decorrentes do convênio PAEC $^{14}$ e demais candidatos). É importante destacar que não foi encontrada nenhuma lista publicada com candidatos selecionados para o curso, em nenhum dos sites com o domínio .unifap.br. Entretanto, em conversa com P3, informações significativas sobre o processo de elaboração e execução do curso foram dadas:

P3: Então, quando eu trabalhei com a supervisão do P5, o trabalho era bem livre. Ele me indicou um site de planos de aula de português como língua estrangeira pra ajudar a montar minhas aulas e me deixou bem à vontade pra fazer o que eu quisesse, contanto que trabalhasse tanto a parte oral quanto a escrita. Eu trabalhava mais o desenvolvimento da fala e inserção na cultura brasileira porque era o que eu pessoalmente achava mais interessante, então trazia muitos textos pra comparar português padrão e português informal, etc. A média de alunos era 6 , por aí. O máximo que tive em sala de aula foi 10 e o mínimo 2. Eles não eram muito assíduos e houve muitas desistências. (Conversa informal realizada em 11/08/2017)

Mais uma vez, nota-se um esforço das partes diretamente envolvidas com o curso para a sua execução. P3 afirma que trabalhou com base no que considerava interessante e ainda nas indicações do que P5 lhe havia indicado e exigido (o trabalho com as habilidades oral e escrita). Ou seja, apesar da formalidade apresentada pela universidade, que é oportuna já que o curso anterior havia tido êxito, de acordo com o que foi dito por P1, não houve efetiva preocupação com o que seria lecionado no curso, tampouco um planejamento inicial. E como mostra a fala de P3, houve falta de assiduidade e desistências por parte dos alunos - o que pode indicar o pouco comprometimento com a aprendizagem de PLA. Nessa direção, a possível política linguística oficial que aqui se configurou não parece ter obtido o mesmo êxito que a política linguística de facto vista anteriormente.

\footnotetext{
${ }^{14}$ Programa de Alianças para a Educação e a Capacitação, promovido pela Organização dos Estados Americanos (OEA). De acordo com informações obtidas com P1, neste curso não houve inscritos advindos deste convênio. Maiores informações sobre o PAEC podem ser consultadas em<http://www.dce. mre. gov.br/ oportuni dades/ OI/ OEA/PAEC.php>.
} 
REVISTA X, Curitiba, volume 13, n.1, p. 323-350, 2018.

Dossiê Especial: Português como Língua Adicional em contextos de minorias:

(co)construindo sentidos a partir das margens

BIZON \& DINIZ (Orgs.)

\section{Curso de Pronúncia em Português para Falantes de Espanhol}

Em uma ação que remete à primeira aqui elencada, o Curso de Pronúncia em Português para Falantes de Espanhol se configurou, em 2016, como o terceiro gesto da universidade com relação ao ensino-aprendizagem de PLA. Assim como a primeira ação, a única convocatória deste curso foi emitida em forma de notícia no site da UNIFAP, conforme mostra a Figura 3, na contramão do que havia sido feito no curso "Português para Estrangeiros", o qual teve caráter mais formalizado.

\section{UNIFAP}

Universidade Federal do Amapá

Até o dia 22 de janeiro, estarão abertas as inscriçōes para o curso de extensão "Pronúncia em Português para Falantes de Espanhol", promovido pelo grupo de pesquisa sobre Ensino de Linguas para Fins Especificos (GP LIFEJUNIFAP). Ministrado pelas professoras o curso é destinado a cidadāos estrangeiros falantes nativos da lingua espanhola que queiran aperfeiçoar a sua pronúncia em português. Com uma duração de 16 horas, as aulas acontecerão nos dias 23 e 30 de janeiro e 13 e 20 de fevereiro, das $9 \mathrm{~h}$ às $12 \mathrm{~h} 20 \mathrm{~m}$. Todos os participantes serão certificados.

Figura 3: Notícia sobre curso de Pronúncia em Português para Falantes de Espanhol

Fonte: http://www.unifap.br/public/index/view/id/6979

A matéria traz informações breves sobre o curso, como público-alvo (cidadãos estrangeiros falantes nativos de espanhol), duração (16 horas no total, 3 horas por dia das $9 \mathrm{~h}$ às 12h20) e período de execução (entre os dias 23 e 30 de janeiro de 2016 e 13 e 20 de fevereiro de 2016). Sobre as razões para a concepção e oferta do curso, trago, então, a fala de P1, que afirmou ter tido êxito na execução do curso pontual para o Celpe-Bras e que, por conta disso, um grupo de pesquisa foi idealizado para o trabalho com línguas para fins específicos: 
REVISTA X, Curitiba, volume 13, n.1, p. 323-350, 2018.

Dossiê Especial: Português como Língua Adicional em contextos de minorias:

(co)construindo sentidos a partir das margens

BIZON \& DINIZ (Orgs.)

Pesquisador: Ah, então o trabalho com PLE fez com que surgissem ações para além do ensino-aprendizagem?

P1: Sim, sim, nós montamos um grupo de pesquisa sobre uso de língua para fins específicos e desse grupo surgiu até outro curso que foi mais focado em falante de espanhol que estavam chegando no Amapá. No caso, os médicos cubanos, e outros também que já estavam aqui e que queriam aprender. Aí o curso foi direcionado pra pesquisa também. (Entrevista concedida em 13/07/2017)

Assim, constata-se que, decorrente da criação do grupo de pesquisa, o Curso de Pronúncia em Português para Falantes de Espanhol foi concebido também como forma de obtenção de registros para o que esses grupos de pesquisa objetivavam focalizar. É importante notar, também, que o público-alvo desse curso era, majoritariamente, os médicos cubanos advindos do Programa Mais Médicos implementado pelo Ministério da Saúde em 2013 ${ }^{15}$. De acordo com o depoimento de P1, constatou-se, assim como no Curso livre de Português para Estrangeiros com foco no Celpe-Bras, movimentos de construção de uma política linguística de facto, partindo, desta vez, do objetivo principal de realizar pesquisa com registros gerados nesse contexto. Quando questionado sobre os desdobramentos do curso, P1 não soube informar detalhadamente aspectos como número de alunos do curso ou metodologia adotada, entretanto, afirmou que esta ação teve como efeitos

P1: [...] a participação de monitores do curso de Letras/Francês, que [...] nos auxiliaram e deram suporte nas aulas a esses alunos [...]. Esses monitores também foram orientados por nós nas pesquisas e fizeram trabalhos com os dados das aulas [...]. Alguns até apresentaram trabalhos em congressos. (Entrevista concedida em 13/07/2017)

Ao explorar a questão da pesquisa a partir do Curso de Pronúncia em Português para Falantes de Espanhol, a narrativa de P1 indica o potencial da área de PLA para além de ações em nível de extensão, ampliando a participação nessas ações para os discentes de graduação não apenas na docência, como também na pesquisa.

15 Mais informações sobre o Programa Mais Médicos podem ser encontradas no site $<$ http://maismedicos.gov.br/> 
REVISTA X, Curitiba, volume 13, n.1, p. 323-350, 2018.

Dossiê Especial: Português como Língua Adicional em contextos de minorias:

(co)construindo sentidos a partir das margens

BIZON \& DINIZ (Orgs.)

\section{Português para Iniciantes}

De forma semelhante ao primeiro e terceiro curso descritos, a quarta ação da

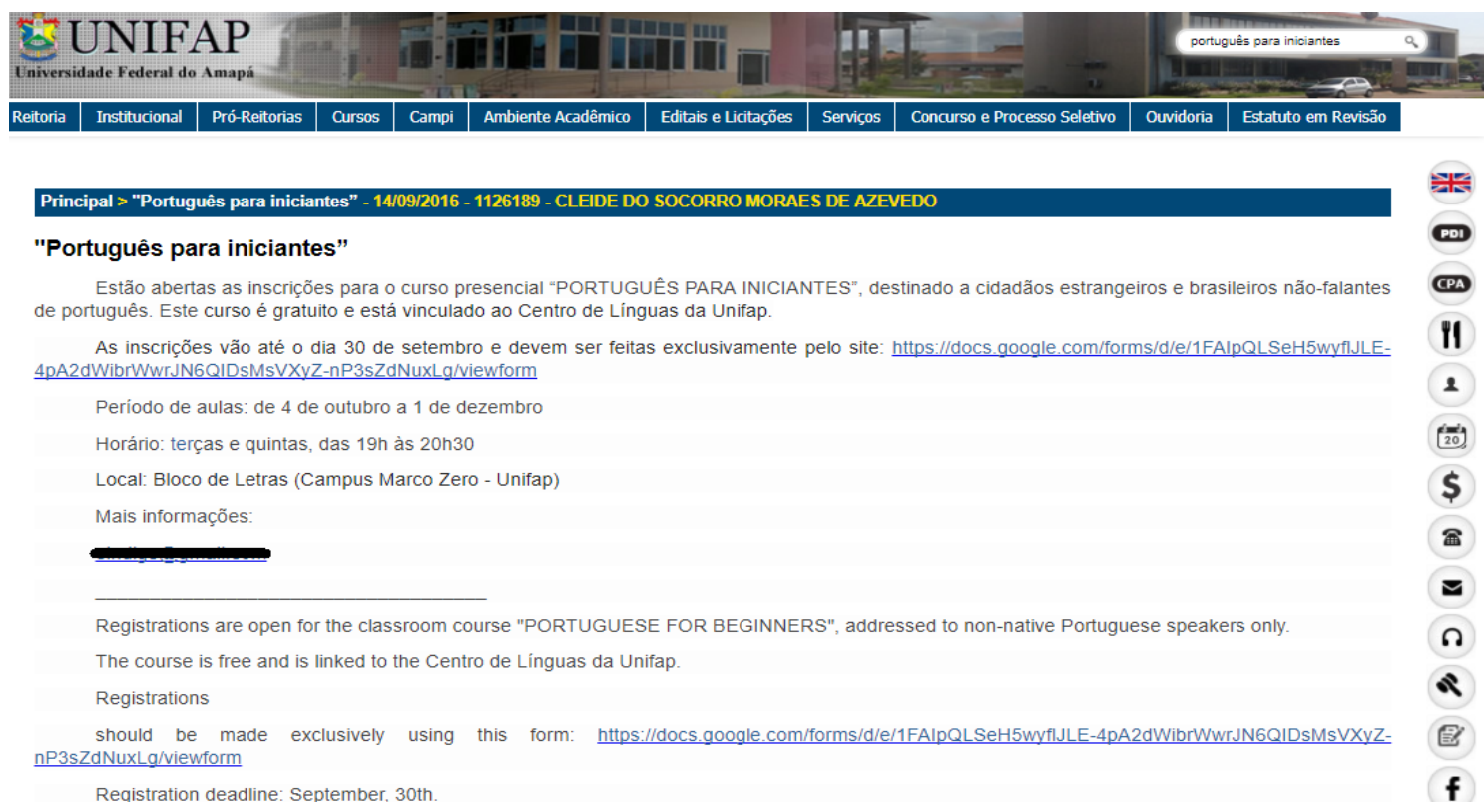

universidade direcionada ao ensino-aprendizagem de PLA e realizada em 2016, o curso

Português para Iniciantes, também foi divulgada apenas por uma notícia no site institucional.

Figura 4: Notícia no site da UNFAP sobre curso de Português para Iniciantes.

Fonte: http://www.unifap.br/public/index/view/id/7848

Ao procurar os responsáveis pela oferta deste curso, não tive êxito na obtenção de informações. Logo, o que se sabe é o que está na notícia ilustrada na Figura 4: tratase de um curso livre de português para falantes de outras línguas, em nível iniciante ou seja, assemelha-se ao segundo curso aqui elencado.

Além de informações sobre o período e horário de execução do curso (de 4 de outubro de 2016 a $1^{\circ}$ de dezembro de 2016, às terças e quintas-feiras, das $19 \mathrm{~h}$ às 20h30), é bastante relevante a matéria mencionar que ele se vincula ao Centro de Línguas da UNIFAP. No site da instituição, não há nenhum documento que prove a 
REVISTA X, Curitiba, volume 13, n.1, p. 323-350, 2018.

Dossiê Especial: Português como Língua Adicional em contextos de minorias:

(co)construindo sentidos a partir das margens

BIZON \& DINIZ (Orgs.)

existência desse centro, tendo sido encontrada apenas a publicação de um edital de pregão eletrônico, datado de maio de 2017, para a construção do prédio, conforme mostra a figura a seguir:

\title{
UNIVERSIDADE FEDERAL DO AMAPÁ - UNIFAP
}

\author{
PROCESSO NN $23125.000692 / 2016-51$ \\ RDC-ELETRÔNICO N 05/2017-UNIFAP \\ EDITAL DO RDC- ELETRÔNICO OBJETIVANDO A CONSTRUÇÃO DO PRÉDIO DE LETRAS E \\ ARTES - CENTRO DE LINGUAS DA FUNDAÇÃO UNIVERSIDADE FEDERAL DO AMAPÁ-UNIFAP, \\ CONFORME CONSTA NOS ANEXOS DESTE EDITAL. \\ MODALIDADE: REGIME DIFERENCIADO DE CONTRATAÇÕES PÚBLICAS (RDC) \\ TIPO DE LICITAÇÃO: MENOR PREÇO \\ OBJETO: CONSTRUÇÄO DO PRĖDIO DE LETRAS E ARTES - CENTRO DE LINGUAS DA FUNDAÇĀO \\ UNIVERSIDADE FEDERAL DO AMAPÁ - UNIFAP. \\ SEÇẢO PÜBLICA DA LICITAÇÄO: \\ I- PRAZO PARA ENVIO DE PROPOSTA: A partir de 18/05/2017 até às 09:59 horas de 08/06/2017 \\ II- DATA DA ABERTURA: 08/06/2017 \\ III- HORA DA ABERTURA: 10:00 horas (Horário de Brasília) \\ IV- FORMALIZACÃO DE CONSULTAS E EDITAL: Comissão Especial - RDC
}

Figura 5: Extrato de edital de pregão eletrônico para construção do Centro de Línguas da UNIFAP

Fonte: http://www.unifap.br/public/index/view/id/8747

A vinculação do curso Português para Iniciantes ao inexistente Centro de Línguas da instituição pode demonstrar um certo movimento em busca de legitimidade para uma política linguística de facto. Pode-se dizer que o pouco detalhamento dos documentos que descrevem os cursos oferecidos já indicia a ausência de solidez na concepção dos mesmos. Nesse contexto, é significativo pensar que, como parte de um processo de internacionalização muito mais vertical e, de certa forma, opressivo (ANDREOTTI et. al., ibidem), a ausência do Centro de Línguas da UNIFAP, associada a uma política de ensino de PLA caracterizada como de facto, reflete considerável discrepância entre os interesses das horizontalidades e das verticalidades (SANTOS, ibidem). Vale lembrar que, na perspectiva de internacionalização adotada neste trabalho, é fundamental que as universidades estabeleçam políticas que 
REVISTA X, Curitiba, volume 13, n.1,p.323-350, 2018.

Dossiê Especial: Português como Língua Adicional em contextos de minorias:

(co)construindo sentidos a partir das margens

BIZON \& DINIZ (Orgs.)

estejam claramente formuladas, fazendo parte de um projeto articulado em todas as instâncias da instituição. Nesse sentido, não é possível que a internacionalização se efetive de maneira sustentável sem que as instituições incluam no documento de sua Missão o que entendem, afinal, por internacionalização, e sem que, no cerne dessa conceituação, esteja a noção de processo, e não apenas de atividade (BIZON, 2013, p. 47).

\section{Curso de Português para Candidatos ao Programa Estudantes Convênio de Graduação}

O Programa Estudantes Convênio de Graduação (PEC-G) ${ }^{16}$, programa de intercâmbio promovido pelo Ministério das Relações Exteriores (MRE), Ministério da Educação (MEC) e pelas IES brasileiras, está em funcionamento desde 1965 e tem por objetivo central a vinda de estudantes estrangeiros originários de países em desenvolvimento para realização de estudos de graduação no Brasil. Dentre as exigências ${ }^{17}$ para participação no programa, os candidatos precisam apresentar o CelpeBras e, para os candidatos que não dispõem da aplicação do exame em seus países, IES credenciadas ofertam cursos preparatórios de língua portuguesa para o exame. Em contrapartida, ainda que o PEC-G já apresente certa tradição no contexto de internacionalização brasileiro, o convênio é recente na UNIFAP. Apenas em 2017 houve a recepção de candidatos ao convênio na instituição para a realização deste curso - o que mereceu destaque em veículos midiáticos, como o da matéria que figura a seguir:

\footnotetext{
${ }^{16}$ Maiores detalhamentos sobre o PEC-G, além do que se pode consultar na página do convênio no site do Ministério das Relações Exteriores (http://www.dce.mre.gov.br/PEC/PECG.php), podem ser obtidos em trabalhos recentes como os de Bizon (2013), Cabral (2015) e Miranda (2016).

${ }^{17}$ Sobre as disposições gerais acerca do PEC-G, é possível consultar o decreto $\mathrm{n}^{\circ} 7.948$, de 12 de março de 2013, disponível em: http://www.planalto.gov.br/ccivil_03/_ato2011-2014/2013/decreto/d7948.htm. Acesso em 10 jun. 2018.
} 
REVISTA X, Curitiba, volume 13, n.1, p. 323-350, 2018.

Dossiê Especial: Português como Língua Adicional em contextos de minorias:

(co)construindo sentidos a partir das margens

BIZON \& DINIZ (Orgs.)

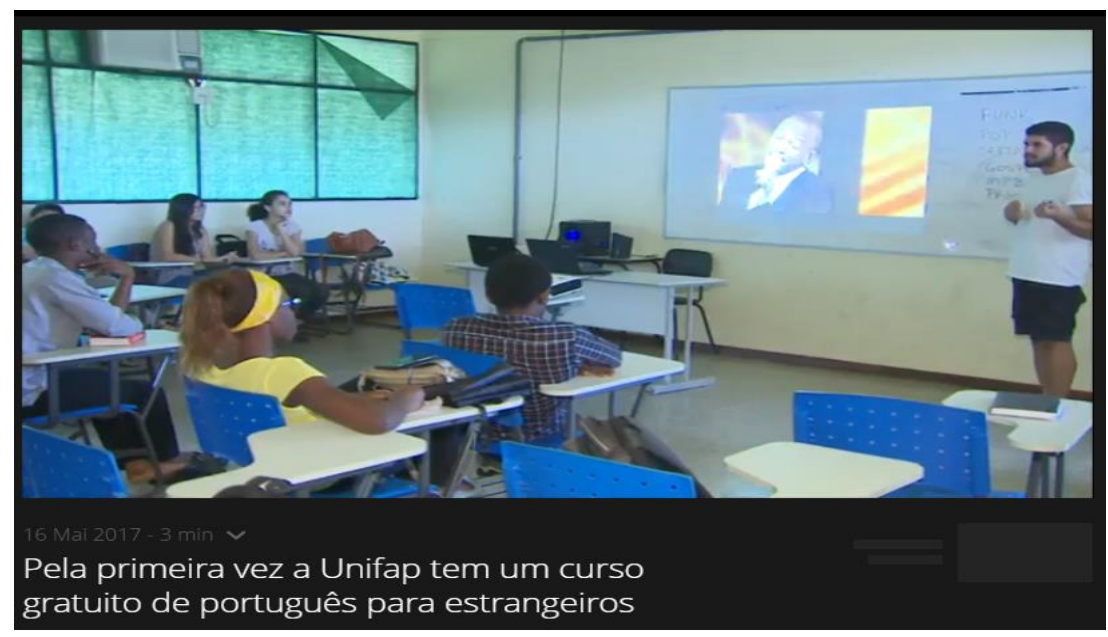

Figura 6: Print de reportagem do portal Globo Play sobre o "primeiro" curso de Português para Estrangeiros

Fonte: https://globoplay.globo.com/v/5873090/

Ao contrário do que traz a manchete, este não é o primeiro curso voltado ao ensino de PLA na instituição. Segundo informações obtidas a partir de entrevista semiestruturada com o participante de pesquisa denominado P2, a mídia televisiva, na ânsia pelo alcance da notícia e em virtude do número alto de candidatos atingidos pelo curso, não se preocupou em elencar cursos anteriores de PLA, ainda que fossem "menores":

Pesquisador: P2, como aconteceu esse processo de elaboração e oferta do curso de PLE para os candidatos ao PEC-G?

P2: Então, antes de mais nada, você deve ter visto na mídia que falaram que esse é o primeiro curso de português pra estrangeiro aqui na UNIFAP. Não é. Tivemos outros cursos com menor alcance, mas este teve o diferencial de atender muitos alunos, 20 nesse caso. E é a primeira vez que a universidade oferta um curso desse porte exclusivo para alunos candidatos ao PEC-G, então houve essa confusão. (Entrevista concedida em 10/07/2017)

Logo, P2 mostra-se atento às ações anteriores a esta, categorizando-as como de "menor alcance" - alcance este que não foi explicitado em sua fala. Infiro que o desconhecimento de P2 quanto à concepção e execução dos cursos anteriores e apenas sua ciência referente à existência desses cursos fez com que houvesse essa categorização entre "maior" e "menor alcance. É válido ressaltar que este professor está diretamente ligado à Pró-Reitoria de Cooperação e Relações Interinstitucionais 
REVISTA X, Curitiba, volume 13, n.1, p. 323-350, 2018.

Dossiê Especial: Português como Língua Adicional em contextos de minorias:

(co)construindo sentidos a partir das margens

BIZON \& DINIZ (Orgs.)

(PROCRI), cuja função está relacionada, dentre outros fatores, ao cumprimento da meta do PDI da UNIFAP mencionado no início deste tópico.

Dito isto, esclareço a estruturação do curso a partir de outra entrevista realizada com P4, co-idealizador e coordenador do curso em parceria com P2:

Pesquisador: P4, como esse curso está estruturado?

P4: Bom, esses alunos têm uma carga horária semanal de 6 horas, sendo que essas 6 horas são divididas em 2 dias. São 3 horas de produção oral e escrita e 3 horas de compreensão oral e escrita ministradas por duas alunas do curso de letras que são bolsistas do curso. Ah, e também tem os professores colaboradores, que são dois monitores do curso de letras e um de relações internacionais que estão nos ajudando também dando aulas para esses alunos no período da tarde.

Pesquisador: De que são essas aulas?

P4: Principalmente de reforço das aulas da manhã e de conversação. (Entrevista concedida em 06/07/2017)

A narrativa de P4 aponta para uma mobilização maior de pessoal para operacionalização deste curso e para a construção coletiva de uma política linguística oficial, que exigiu bastante de diversas partes. Conforme visto anteriormente, esta ação foi um esforço coletivo de três grandes grupos: a administração, na figura da PROCRI; o curso de Letras, na figura dos professores coordenadores; e os professores-monitores (sendo que, neste caso, duas monitoras receberam bolsa, e outros três monitores auxiliaram de forma voluntária nas aulas da tarde, de acordo com P4). Com relação a essa mobilização local, vale destacar a narrativa de P2 quando questionado sobre os percalços encontrados na elaboração deste curso:

P2: Nem o MEC [Ministério da Educação], nem o MRE [Ministério das Relações Exteriores] ... Não existiu nenhum tipo de suporte pra gente. Então assim, a gente não sabia nem qual carga horária dar pra esses alunos. Pode talvez parecer óbvio pra quem já tem alguma experiência, mas pra gente não foi. A gente não sabia se dava duas horas... aulas semanais, quatro aulas semanais... Isso foi uma dificuldade e a gente foi tateando... a gente fez do jeito que achava melhor possível. Mas não tem assistência; o MEC pede pra abrir [cursos de PLA], mas não tem nenhuma diretriz pra isso. (Entrevista concedida em 10/07/2017)

Nesse trecho, é possível constatar como as decisões tomadas a partir de uma verticalidade podem acarretar, de maneira direta, políticas linguísticas de facto, e como 
REVISTA X, Curitiba, volume 13, n.1, p. 323-350, 2018.

Dossiê Especial: Português como Língua Adicional em contextos de minorias:

(co)construindo sentidos a partir das margens

BIZON \& DINIZ (Orgs.)

a ausência de um suporte é crucial para a elaboração de um curso, especialmente quando se trata de universidades que estão "tateando", conforme a fala do próprio professor, no que concerne à internacionalização. Também se faz necessário destacar o quão complexa é a discrepância entre os interesses e imposições de uma verticalidade (nesse caso, o MEC) e quem faz estas determinações acontecerem. É certo que houve significativa mobilização de pessoal para a construção desta política de ensino de língua em particular e que, sem esta mobilização, o curso não teria existido. Entretanto, não se pode perder de vista que isso tudo partiu de uma ordem superior, sem que houvesse condições mínimas para o estabelecimento da dita "cooperação" almejada pelo convênio em questão.

Desse modo, cabe destacar que não apenas no contexto amapaense, mas no contexto de universidades que surgiram na modernidade recente, a exigência da internacionalização das IES acaba se tornando um reflexo direto de uma globalização que, muitas vezes, faz imposições imponderáveis para contextos em que as primeiras ações de política linguística - particularmente de PLA - estão sendo implementadas. Acaba-se, assim, por exigir uma mobilização que já deveria, minimamente, ter sido estabelecida em uma política linguística oficial. É o caso deste último curso de PLA analisado.

\section{(IN)CONCLUSÕES}

P2: Então eu acho que a partir daí a gente vai ter uma nova área fundamental dentro da universidade e com forte capacidade de internacionalização, que é o ensino de português para estrangeiro. (Entrevista concedida em 10/07/2017)

Ao final da entrevista com todos os professores, foi solicitado que explanassem suas visões sobre o futuro do ensino-aprendizagem de PLA não só na universidade, mas no Amapá de uma forma mais geral. Dentre as várias respostas que emergiram, destaco a narrativa de P2, que define a área de PLA como um eixo fundamental a partir do qual poderá se desenvolver a internacionalização da instituição. 
REVISTA X, Curitiba, volume 13, n.1, p. 323-350, 2018.

Dossiê Especial: Português como Língua Adicional em contextos de minorias:

(co)construindo sentidos a partir das margens

BIZON \& DINIZ (Orgs.)

Conforme supracitado, a UNIFAP é uma universidade jovem, assim como muitas outras instituições distribuídas pelo Brasil, e que também necessita atender aos interesses de uma verticalidade que impõe a instância da internacionalização como um dos pontos centrais para seu desenvolvimento. É certo que a noção de “desenvolvimento" institucional, frequentemente imposta por instâncias superiores, não é acompanhada por um guia ou manual para execução dessas ações. Conforme as narrativas aqui trazidas, políticas de promoção do PLA na UNIFAP têm emergido, em sua maioria, a partir de iniciativas horizontais gerenciadas e executadas por agentes sociais locais, sem um adequado suporte das ditas verticalidades.

Mais uma vez, destaco que ações de internacionalização precisam ser viabilizadas para além de possíveis impactos que possam gerar em relação a números e rankings, resistindo a discursos que projetam a internacionalização como um processo "desenvolvimentista" e, portanto, muito mais mercadológico do que formativo. Nesse sentido, chama a atenção o fato de que, em nenhum momento, nas narrativas analisadas, foram citadas ações existentes ou desejáveis para o PLA em contextos de minorias/minoritarizados, como PLA para surdos, PLA para indígenas ou, para citar um contexto mais familiar à internacionalização das IES, o PLA para migrantes de crise (refugiados ou com visto humanitário) - mesmo estes dois últimos contextos sendo parte integrante da realidade fronteiriça na qual a UNIFAP se encontra e de uma representação de "margem" da qual é parte.

Embora a universidade tenha promovido cursos voltados aos médicos cubanos e a estudantes do PEC-G - o que aproximaria a instituição de uma perspectiva de internacionalização menos mercadológica -, ainda assim salta aos olhos o apagamento desses outros contextos de PLA anteriormente citados. Apagamento este que pode ter relação com o fato de estarmos imersos em uma concepção de internacionalização ainda bastante convencional, frequentemente tida como sinônimo de mobilidade estudantil por meio de intercâmbios e de convênios de cooperação internacional, com a língua portuguesa sendo ensinada como "língua estrangeira". Apagamento este que também alerta para uma certa incongruência entre o "estar na(s) margem(ens)" e o "apagar a(s) própria(s) margem(ens)". 
REVISTA X, Curitiba, volume 13, n.1, p. 323-350, 2018.

Dossiê Especial: Português como Língua Adicional em contextos de minorias:

(co)construindo sentidos a partir das margens

BIZON \& DINIZ (Orgs.)

As considerações aqui trazidas, longe de pretenderem traçar conclusões, iluminam a complexidade da implantação e do gerenciamento de políticas de ensino do PLA nesse particular momento de propagação da internacionalização como uma necessidade institucional. Parte dessa complexidade se traduz na afirmação de P2 que abre estas (in)conclusões.

Assim, tomando esse cenário inicial desenhado pelas ações de promoção do Português como Língua Adicional na UNIFAP, considero ser fundamental ampliar o conhecimento dos processos de internacionalização nas IES, discutindo-se o que pode significar ter o PLA como uma "nova área fundamental" com "forte capacidade de internacionalização". Discussão esta que, a meu ver, não pode prescindir de um diálogo efetivo entre horizontalidades e verticalidades, de modo que ações institucionais de políticas linguísticas possam se traduzir em uma acepção de desenvolvimento que implique inserção e cidadania para todos aqueles que, fazendo parte das horizontalidades, são os que, efetivamente, constituem as IES e seus processos de internacionalização.

\section{REFERÊNCIAS}

$\begin{array}{lrrrrr}\text { AMAPÁ. Plano de Prevenção e Controle do Desmatamento e Queimadas do } \\ \text { Estado } & \text { do } & \text { Amapá. } & 2009 . & \text { Disponível } & \text { em: }\end{array}$ <http://www.fundoamazonia.gov.br/FundoAmazonia/ ex por/sites/default/site_pt/Galerias/Arquivos/Publicacoes/Plano_Estadual_do_Amapa.pdf >. Acesso em 6 jun. 2017.

ANDREOTTI, V. et al. Mapping interpretations of decolonization in the context of higher education. Decolonization: Indigeneity, Education \& Society, v. 4, n. 1, p. 2140, 2015.

BIZON, A. C. C. Narrando o exame Celpe-Bras -Bras e o convênio PEC-G: a construção de territorialidades em tempos de internacionalização. 2013. 415 p. Tese (Doutorado em Linguística Aplicada). Universidade Estadual de Campinas, Campinas, 2013. Disponível em: <http://www.bibliotecadigital.unicamp.br/document/?code $=000911713 \&$ opt=4>. Acesso em: 6 jun. 2017.

BIZON, A. C. C; CAMARGO, H. R. E. Acolhimento e ensino da língua portuguesa à população oriunda de migração de crise no município de São Paulo: por uma política do atravessamento entre verticalidades e horizontalidades. In: BAENINGER, R.; MOREIRA, J. B.; VEDOVATO, L. R.; SOUZA, M. R.; DEMÉTRIO, N. B.; 
REVISTA X, Curitiba, volume 13, n.1, p. 323-350, 2018.

Dossiê Especial: Português como Língua Adicional em contextos de minorias:

(co)construindo sentidos a partir das margens

BIZON \& DINIZ (Orgs.)

DOMENICONI, J. O. S.; FERNANDES, A.; MONTEIRO, V. P. (Org.). Migrações Sul-Sul. 2a.ed.Campinas, SP: Núcleo de Estudos de População - Nepo/Unicamp, v. 01, p. 712-726, 2018.

CABRAL, F. M. A. Os estudantes africanos nas instituições de ensino superior brasileiras: o Programa de Estudante Convênio de Graduação (PEC-G). 2015. 204 p. Dissertação (Mestrado em Sociologia). Universidade Federal do Rio Grande do Sul, Porto Alegre, 2015. Disponível em: < http://www.lume.ufrgs.br/handle/10183/131630>. Acesso em: 7 dez. 2017.

CALVET, J. L. As políticas linguísticas. São Paulo: Parábola Editorial, 2007.

DINIZ, L. R. A. Para além das fronteiras: a política linguística brasileira de promoção internacional do português. Belo Horizonte: UFMG, no prelo.

FLICK, U. Introdução à pesquisa qualitativa. $3^{\text {a }}$ ed. Porto Alegre: Artmed, 2009.

HALL, S. Da diáspora: identidades e mediações culturais. Belo Horizonte: Editora da UFMG, 2009.

KRAWCZYK, N. R. As políticas de internacionalização das universidades no Brasil: o caso da regionalização no Mercosul. Jornal de Políticas Educacionais, n. 4, p. 41-52, jul./dez 2008.

LANKSHEAR, C.; KNOBEL, M. Pesquisa Pedagógica: do projeto à implementação. Porto Alegre: Artmed, 2008.

MAHER, T. J. M. O desejo de retorno da língua (quase) perdida: professores indígenas e identidade linguística. Revista da FAEEBA - Educação e Contemporaneidade, Salvador, v. 19, n. 33, p. 147-158, jan./jun. 2010.

MIRANDA, Y. C. C. Projeto "Pelo Mundo": a configuração de uma política linguística em um curso de Português como Língua Adicional para candidatos ao Programa de Estudantes Convênio de Graduação (PEC-G). 2016. 178 p. Dissertação (Mestrado em Estudos Linguísticos). Universidade Federal de Minas Gerais, Belo Horizonte, 2016. Disponível em: < http://www.bibliotecadigital.ufmg.br/dspace/handle/ 1843/RMSA-AHNGP5>. Acesso em: 3 out. 2017.

PENNYCOOK, A. Uma linguística aplicada transgressiva. In: LOPES, L. P. M. (org.) Por uma linguística aplicada INdisciplinar. São Paulo: Parábola Editorial, 2006, p.67-84.

Global Englishes and transcultural flows. London and New York: Routledge, 2007. 
REVISTA X, Curitiba, volume 13, n.1, p. 323-350, 2018.

Dossiê Especial: Português como Língua Adicional em contextos de minorias:

(co)construindo sentidos a partir das margens

BIZON \& DINIZ (Orgs.)

RAJAGOPALAN, K. Linguistics and the myth of nativity: comments on the controversy over 'new/non-native' Englishes. Journal of Pragmatics, v. 27, p. 225-231, 1997.

SANTOS, F. R. História do Amapá. 6 ed. Macapá: Gráfica e Editora Valcan, 2000.

SANTOS, M. Por uma outra globalização. Do pensamento único à consciência universal. Rio de Janeiro: Editora Record, 2001

SCARAMUCCI, M. V. R. O exame Celpe-Bras -Bras e a proficiência do professor de português para falantes de outras línguas. Revista DIGILENGUAS, n. 12, p. 48-67, jun. 2012.

SHOHAMY, E. Language policy: hidden agendas and new approaches. London: Routledge, 2006.

SILVA, I. Políticas linguísticas em um contexto transfronteiriço: representações de professores sobre o Pacto Nacional pelo Fortalecimento do Ensino Médio - PNEM. 2016. 148 p. Dissertação (Mestrado em Sociedade, Cultura e Fronteiras). Universidade Estadual do Oeste do Paraná, Foz do Iguaçu, 2016. Disponível em: < http://tede.unio este.br/ bit str ea m /tede/ 2 578/1/Izabel_Silva_2016.pdf>. Acesso em: 30 jul. 2018.

SPOLSKY, B. Language Policy. Cambridge: Cambridge University Press, 2004.

STEIN, S.; ANDREOTTI, V. Cash, competition or charity: international students and the global imaginary. Higher Education, v. 1, n. 72, p. 225-239, 2015.

TEIXEIRA, E. As três metodologias: acadêmica, da ciência e da pesquisa. 7. ed. Petrópolis: Vozes, 2010.

THREADGOLD, T. Performing theories of narrative: theorising narrative performance. In: THORNBORROW, J.; COATES, J. The sociolinguistics of narrative. Amsterdam/ Philadelphia: John Benjamins Publishing Company, 2005, p.261-278. 